Research Article

\title{
Research and Application of Critical Failure Paths Identification Method for Dam Risk Analysis
}

\author{
Kun He, ${ }^{1,2}$ Liang Pei $\mathbb{D}^{1,2}$ Xiang Lu, ${ }^{1,2}$ Jiankang Chen, ${ }^{1,2}$ and Zhenyu $\mathrm{Wu}^{1,2}$ \\ ${ }^{1}$ State Key Laboratory of Hydraulics and Mountain River Engineering, Sichuan University, No. 24 South Section 1 Yihuan Road, \\ Chengdu 610065, China \\ ${ }^{2}$ College of Water Resources \& Hydropower, Sichuan University, No. 24 South Section 1 Yihuan Road, Chengdu 610065, China
}

Correspondence should be addressed to Liang Pei; pl_scu@scu.edu.cn

Received 29 April 2020; Revised 8 August 2020; Accepted 15 September 2020; Published 23 September 2020

Academic Editor: Francesco Clementi

Copyright ( 92020 Kun He et al. This is an open access article distributed under the Creative Commons Attribution License, which permits unrestricted use, distribution, and reproduction in any medium, provided the original work is properly cited.

\begin{abstract}
Dam is an important part of the national infrastructure, and its safety has been widely concerned. Risk identification of dams plays a significant role in risk assessment and control. Finding out some critical failure paths through adopting timely measures can help reduce the risk occurrence probability effectively. This paper develops an identification method based on the credibility and the interval analytic hierarchy process (IAHP) methods, namely, consistency and difference-based interval analytic hierarchy process (CDB-IAHP) method, to identify the critical failure paths of dams exactly considering the dynamic cognition degree of decisionmakers. Based on the fault tree analysis (FTA) method, the framework and analysis for critical failure paths identification of a gravity dam and an Earth-rockfill dam are conducted and made. The results show that the critical failure paths obtained by the proposed method are in line with the statistical data, and the importance of disaster causing factors has some difference with the traditional method. Additionally, some engineering and nonengineering measures are suggested to reduce the impact of potential failure paths. The applications demonstrate that the proposed method shows good applicability for risk analysis and critical failure path mining of dams.
\end{abstract}

\section{Introduction}

Since the twenty-first century, a large number of dams with a height exceeding $200 \mathrm{~m}$ or even $300 \mathrm{~m}$ have been built or are under construction, of which Earth dams and gravity dams account for $91 \%$. The safety of high dams has attracted wide attention due to the complex geology condition and changeable environment. According to statistics, there are 3498 dam failure accidents in China with different failure modes. The failure modes are related to the dam type, geological condition, management, and dispatching, such as the failure modes of instability failure of foundation in gravity dams (St Francis gravity dam in the US), the failure modes of dam break (Shimantan dam in China) and seepage damage (Teton, the clay core dam in USA) in Earth dams, and the failure modes of abutment destabilization (Malpasset dam in France) and landslide surge (Vajont dam in Italy) in arch dams. Diversified failure modes pose great challenges to management. Failure of dams may be avoided through adopting some timely reinforcement measures if the potential critical failure paths could be identified beforehand.

Analytic hierarchy process (AHP) $[1,2]$ is one of the most widely adopted methods for quantitative analysis of qualitative problems. Because of its simplicity and effectiveness, AHP is widely used in many complex decisionmaking fields [3-6], including the risk analysis on dams. Choi et al. [7] studied the quantitative evaluation index and evaluation method of dam safety restoration using the AHP method. Li et al. [8] investigated the dynamic risk analysis of a high rockfill dam during construction based on the AHP method. However, there are still some deficiencies and limitations in the application of AHP. For example, the comparative judgment is highly subjective because it highly relies on the opinions of decision-makers who may have limited knowledge and experience of alternative methods. 
The limitation would lead to the differences in opinions of decision-makers. Fortunately, scholars have developed some theories and methods to solve the deficiencies of AHP. To better deal with the judgment objectively, fuzzy sets were introduced to express decision-makers' evaluations [9-13]. In the field of water and dams, coupled model of fuzzy sets and AHP was also employed, such as the evaluation of dam breaks [14] and the water quality assessment [15]. In addition, the interval analytic hierarchy process (IAHP) method was widely used in the risk identification of dams [16-18]. Although the subjectivity of comparative judgment can be reduced to a certain extent by using the IAHP method, the traditional judgment weight methods (e.g., the arithmetic average method, the weighted geometric mean method, and the weighted arithmetic average method) seldom take the dynamical decision-makers' comparative matrix into account and ignore their cognitive degree on complex decision problems $[19,20]$. To minimize the impact of decision-makers' subjectivity, a credibility index is adopted to display the differences among decision-makers quantitatively $[21,22]$, and then the consistency and difference degree among decision-makers can be determined. However, there is not much research on the methods for the specific critical path identification in dams, the mining of critical failure path is the key step to evaluate the critical risk factors and failure paths of dams, and using the consistency and difference among decision-makers to determine the critical paths of dams plays an important role in the risk evaluation of dams. Because of this, a method considering the consistency and difference among decision-makers is developed.

The objective of this paper is to propose a method for identifying the critical failure paths of dams considering the consistency and difference of comparative judgments among decision-makers. The main contents of the study are as follows: (a) based on the IAHP method, the consistency and difference degree analysis of the judgment matrices for disaster causing factors in dams are studied, and then the credibility of decision-makers is determined; (b) the subjective weight and objective weight are adopted to reflect the cognitive degree of decision-makers on complex decision problems, and the ranking method is determined; (c) taking the Guandi gravity dam and the Pubugou Earth-rockfill dam as examples. The application of the proposed method in identifying the critical path of the dam was discussed.

\section{Methodology}

To make full use of the decision-makers judgment matrix on the set of the disaster-causing factors and reduce the influence of decision-makers' subjectivity on failure path identification in dams, the interval analysis hierarchy process (IAHP) combined with the credibility theory, including the consistency and difference (named CDB-IAHP), is introduced to identify the critical failure paths in dams. Based on the fault tree analysis (FTA) method, the CDB-IAHP method integrating the interval analytic hierarchy process, consistency, and difference of decision-makers is applied to a gravity dam and an Earth-rockfill dam. The critical failure paths of dams are compared with the statistics of failure paths. The methodology is shown in Figure 1.

2.1. IAHP Method. Interval analytic hierarchy process (IAHP) uses quantitative intervals instead of a certain value to describe the relative importance of indexes. The upper and lower limits of quantitative intervals can be determined by a standardized comparison scale of nine levels (Table 1).

Matrix $\mathbf{A}_{k l}^{p}$ is defined as a comparative judgment matrix based on the hierarchical structure formed by the nine-level method. $\mathbf{A}_{k l}^{p}$ can be expressed as

$$
\begin{aligned}
\mathbf{A}_{k l}^{p} & =\left[\mathbf{A}_{k l}^{p-}, \mathbf{A}_{k l}^{p+}\right], \\
\mathbf{A}_{k l}^{p-} & =\left(a_{k l i j}^{p-}\right)_{n \times n}, \\
\mathbf{A}_{k l}^{p+} & =\left(a_{k l i j}^{p+}\right)_{n \times n}, \\
a_{k l i j}^{p-} & =\frac{1}{a_{k l j i}^{p+}}, \quad \frac{1}{9} \leq a_{k l i j}^{p-} \leq a_{k l i j}^{p+} \leq 9,
\end{aligned}
$$

where $\mathbf{A}_{k l}^{p}$ represents the judgment matrix for the $l^{\text {th }}$ index evaluation set in the $k^{\text {th }}$ level from decision-maker $p(p=1,2, \ldots, m) ; m$ denotes the number of decisionmakers; $a_{k l i j}^{p-}$ and $a_{k l i j}^{p+}$ represent the upper and lower limits of the relative importance of the indexes $i$ and $j$ for the $l^{\text {th }}$ index evaluation set in the $k^{\text {th }}$ level from decision-maker $p ; k$ denotes the level number of hierarchical structure; $l$ denotes the number of index evaluation sets in each level.

The judgment matrix often has an important impact on the analysis results, so the consistency test of the interval judgment matrix is needed [23]. For any two interval numbers $\bar{a}_{k l i j}^{p}=\left[a_{k l i j}^{p-}, a_{k l i j}^{p+}\right]$ and $\bar{b}_{k l i j}^{p}=\left[b_{k l i j}^{p-}, b_{k l i j}^{p+}\right]$ in equation (1), the multiplication and reciprocal operation of interval numbers are defined:

$$
\overline{a_{k l i j}^{p} b_{k l i j}^{p}}=\left[a_{k l i j}^{p-} \cdot b_{k l i j}^{p-}, a_{k l i j}^{p+} \cdot b_{k l i j}^{p+}\right], \frac{1}{\overline{a_{k l i j}^{p}}}=\left[\frac{1}{a_{k l i j}^{p+}}, \frac{1}{a_{k l i j}^{p-}}\right] .
$$

When $1 \leq i, j, t \leq n$, we have

$$
\overline{a_{k l i j}^{p} a_{k l j t}^{p}}=\overline{a_{k l j j}^{p} a_{k l i t}^{p}}, \overline{a_{k l i j}^{p}}=\frac{1}{\overline{a_{k l i j}^{p}}}, \overline{a_{k l j j}^{p}}=[1,1] .
$$

Then, matrix $\mathbf{A}_{k l}^{p}$ can be considered to meet the consistency and $\mathbf{A}_{k l}^{p}$ is the consistent interval number judgment matrix [24].

\subsection{CDB-IAHP Method for Failure Path Identification on Dams}

2.2.1. Consistency and Difference Analysis of Weight Data. It is known that there are still some deficiencies and limitations in the application of AHP or IAHP, and the path identification on dams plays an important role in the risk analysis of dams. Although the number of decision-makers is enough and their knowledge and experience are rich, 

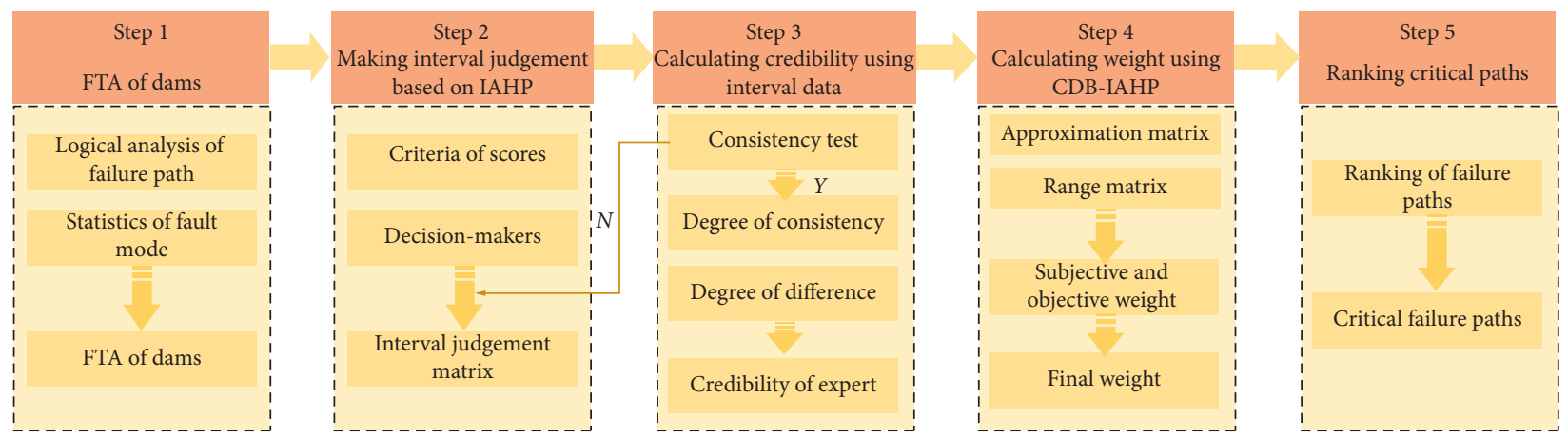

Figure 1: Flowchart for the failure paths identification of dams.

TAвle 1: Nine-point intensity of importance scale and its description.

\begin{tabular}{lc}
\hline Definition & The intensity of importance scale \\
\hline Equally important & 1 \\
Moderately more important & 3 \\
Strongly more important & 5 \\
Very strongly more important & 7 \\
Extremely more important & 9 \\
Intermediate values & $2,4,6,8$ \\
\hline
\end{tabular}

consistency and difference between judgment matrices based on different decision-makers' opinions for the disaster-causing factors in dams exist objectively.
On one hand, the consistency degree $\left(\omega_{p}\right)$ among decision-makers for the disaster-causing factors in dams is often measured by deriving the spatial position relationship between vectors, that is, the cosine value of the angle between two vectors:

$$
\omega_{p}=\frac{\left(\sum_{q=1}^{m}\left(\left(A_{k l}^{\prime p}, A_{k l}^{\prime q}\right) /\left\|A_{k l}^{\prime p}\right\| \cdot\left\|A_{k l}^{\prime} q\right\|\right)-1\right)}{\sum_{q=1}^{m}\left(\sum_{q=1}^{m}\left(\left(A_{k l}^{\prime} p, A_{k l}^{\prime q}\right) /\left\|A_{k l}^{\prime} p\right\| \cdot\left\|A_{k l}^{\prime}\right\|\right)-1\right)},
$$

where $\mathbf{A}_{k l}^{\prime p}$ and $\mathbf{A}_{k l}^{\prime p}$ are the derived vectors of the judgment matrices $\mathbf{A}_{k l}^{p}$ and $\mathbf{A}_{k l}^{q}$ for $l^{\text {th }}$ index evaluation set in the $k^{\text {th }}$ level from decision-makers $p$ and $q$, respectively, and they can be obtained by the following two equations:

$$
\begin{aligned}
& A_{k l}^{\prime p}=\left(a_{k l i^{\prime} j^{\prime}}^{\prime p}\right)_{1 \times 2 n^{2}} \\
& =\left(a_{k l 11}^{p-}, \ldots, a_{\mathrm{kln} 1}^{p-}, \ldots, a_{k l 12}^{p-}, \ldots, a_{\mathrm{kln} 2}^{p-}, \ldots, a_{k l 1 n}^{p-}, \ldots, a_{\mathrm{kln} n}^{p-}, a_{k l 11}^{p+}, \ldots, a_{\mathrm{kln} 1}^{p+}, \ldots, a_{k l 12}^{p+}, \ldots, a_{\mathrm{kln} 2}^{p+}, \ldots, a_{k l 1 n}^{p+}, \ldots, a_{\mathrm{kln} n}^{p+}\right), \\
& A_{k l}^{\prime q}=\left(a_{k l i^{\prime} j^{\prime}}^{\prime q}\right)_{1 \times 2 n^{2}} \\
& =\left(a_{k l 11}^{q^{-}}, \ldots, a_{k \ln 1}^{q^{-}}, \ldots, a_{k l 12}^{q^{-}}, \ldots, a_{k \ln 2}^{q^{-}}, \ldots, a_{k l 1 n}^{q^{-}}, \ldots, a_{k \ln n}^{q^{-}}, a_{k l 11}^{q+}, \ldots, a_{k \ln 1}^{q^{+}}, \ldots, a_{k l 12}^{q+}, \ldots, a_{k \ln 2}^{q^{+}}, \ldots, a_{k l 1 n}^{q^{+}}, \ldots, a_{\mathrm{kln} n}^{q^{+}}\right),
\end{aligned}
$$

where $i^{\prime}=1$ and $j^{\prime}=1,2, \ldots, 2 n^{2}$.

On the other hand, the difference of evaluation value is adopted to express the difference degree among decisionmakers; the difference degree $\sigma_{p}$ between decision-maker $p$ and other decision-makers can be expressed by

$$
\sigma_{p}=\frac{\bar{\Delta}_{p}}{\sum_{p=1}^{m} \bar{\Delta}_{p}, \bar{\Delta}_{p}=\sum_{j^{\prime}=1}^{2 n^{2}}\left|a_{k l i^{\prime} j^{\prime}}^{p}-\bar{a}\right|, \bar{a}=\frac{1}{m} \sum_{p=1}^{m} a_{k l i^{\prime} j^{\prime}}^{\prime},}
$$

where $\bar{\Delta}_{p}$ denotes the sum of the differences between the judgment matrix of decision-maker $p$ and the mean value; $\bar{a}$ is the mean of the relative importance of each index of different decision-makers.

Therefore, the credibility of decision-makers' evaluation results indicates the difference relationship among evaluation results which are jointly determined by the consistency degree and the difference degree [25]. The credibility $\left(\lambda_{p}\right)$ of an expert $p$ can be calculated by

$$
\lambda_{p}= \begin{cases}\omega_{p}, & \left(\sum_{p=1}^{m} \omega_{p} \sigma_{p}=1\right), \\ \frac{\omega_{p}\left(1-\sigma_{p}\right)}{1-\sum_{p=1}^{m} \omega_{p} \sigma_{p}}, & \left(\sum_{p=1}^{m} \omega_{p} \sigma_{p} \neq 1\right) .\end{cases}
$$

2.2.2. Ranking of the Failure Paths in Dams. The error theory is a common method to solve interval weights. The interval weights are calculated based on the consistent approximation matrix and range matrix. 
Assuming that there is an interval judgment matrix $\mathbf{A}=\left(A_{i j}\right)_{n \times n},\left(A_{i j}=\left[a_{i j}^{-}, a_{i j}^{+}\right]\right)$for the disaster-causing factors in dams, the consistent approximation matrix and range matrix of matrix $\mathbf{A}$ can be given based on the error theory.

$$
\begin{aligned}
\mathbf{M} & =\left(m_{i j}\right)_{n \times n^{\prime}} \\
m_{i j} & =\left(\prod_{z=1}^{n} \frac{a_{i z}^{-} a_{i z}^{+}}{a_{j z}^{-} a_{j z}^{+}}\right)^{1 / 2 n}, \\
\Gamma_{1} \mathbf{M} & =\left(\Gamma_{1} m_{i j}\right)_{n \times n}=\left(m_{i j}-a_{i j}^{-}\right)_{n \times n}, \\
\Gamma_{2} \mathbf{M} & =\left(\Gamma_{2} m_{i j}\right)_{n \times n}=\left(a_{i j}^{+}-m_{i j}\right)_{n \times n},
\end{aligned}
$$

where matrix $\mathbf{M}$ is the consistent approximation matrix of matrix $\mathbf{A}$; and matrices $\Gamma_{1}$ and $\Gamma_{2}$ are the two range matrices of matrix $\mathbf{A}$.

Based on equations (10)-(12), the weight vectors $\mathbf{W}$ of matrices $\mathbf{M}, \Gamma_{1}$, and $\Gamma_{2}$ can be expressed as follows:

$$
\begin{aligned}
\mathbf{W} & =\left(w_{1}, w_{2}, \ldots, w_{j}, \ldots, w_{n}\right), \\
w_{j} & =\frac{\left(\prod_{z=1}^{n} a_{j z}^{-} a_{j z}^{+}\right)^{1 / 2 n}}{\sum_{i=1}^{n}\left(\prod_{z=1}^{n} a_{i z}^{-} a_{i z}^{+}\right)^{1 / 2 n}}, \\
\left(\Gamma_{t} w_{j}\right)^{2} & =\frac{\sum_{i=1}^{n}\left(\Gamma_{t} m_{i j}\right)^{2}}{\left(\sum_{i=1}^{n} m_{i j}\right)^{4}}, \quad(t=1,2) .
\end{aligned}
$$

Then, the interval weight $w_{j}^{\prime}$ of interval judgment matrices and the specific interval weight $w_{j}^{p}$ for decisionmaker $p$ can be given by the following two equations, respectively:

$$
\begin{aligned}
& w_{j}^{\prime}=\left(w_{j}-\Gamma_{1} w_{j}, w_{j}+\Gamma_{2} w_{j}\right)=\left(w_{j}^{-}, w_{j}^{+}\right), \\
& w_{j}^{p}=\left(w_{j}^{p-}, w_{j}^{p+}\right) .
\end{aligned}
$$

Generally, the final weight can be calculated by the arithmetic average method, the weighted geometric mean method, and so forth. However, these results cannot reflect the cognitive degree of decision-makers on complex decision problems. Because of this, the subjective and objective weights are adopted to reflect the subjective aspect and the objective aspect of decision-makers' opinions, respectively, as shown in the following two equations:

$$
\begin{gathered}
\omega_{x 1}=\frac{1}{2} \frac{\sum_{p=1}^{n}\left\{\lambda_{p}\left[\left(w_{j}^{p+}\right)^{2}-\left(w_{j}^{p-}\right)^{2}\right]\right\}}{\sum_{p=1}^{n}\left[\lambda_{p}\left(w_{j}^{p+}-w_{j}^{p-}\right)\right]}, \\
\omega_{x 2}=\frac{b_{d j}}{\sum_{j=1}^{n} b_{d j}} .
\end{gathered}
$$

We have $b_{d j}=1 /\left(1+g_{j}\right), \quad g_{j}=\left(\begin{array}{lll}1 / & 3\end{array}\right) \sum_{p=} 1^{n}\left(\lambda_{p}\right.$ $\left.\left[\left[\left(w_{j}^{p+}\right)-\omega_{x 1}\right]^{3}-\left[\left(w_{j}^{p-}\right)-\omega_{x 1}\right]^{3}\right] / \sum_{p=1}^{n} \lambda_{p}\left[\left(w_{j}^{p+}\right)-\left(w_{j}^{p-}\right)\right]\right)$, where $\omega_{x 1}$ is the subjective weight; and $\omega_{x 2}$ is the objective weight [26].

Therefore, the final weight $\omega_{x}$ of disaster-causing factors in dams can be expressed as

$$
\omega_{x}=\frac{\omega_{x 1} \omega_{x 2}}{\sum_{x} \omega_{x 1} \omega_{x 2}} .
$$

\section{Case Studies}

\subsection{Case A: The Guandi Gravity Dam}

3.1.1. Project Review. Guandi hydropower project is located in Liangshan, Sichuan Province. It is composed of a roller-compacted concrete (RCC) dam, a flood discharge structure, an underground powerhouse on the right bank, and so on. The normal water level is $1330.0 \mathrm{~m}$, with a corresponding capacity of $752.8 \mathrm{million} \cdot \mathrm{m}^{3}$. The maximum dam height is $168 \mathrm{~m}$. The elevation of the barrage is about $1334.0 \mathrm{~m}$. The dam crest length is $516.0 \mathrm{~m}$, the lowest base elevation is $1166.0 \mathrm{~m}$, and the maximum dam bottom width is $153.2 \mathrm{~m}$. Guandi hydropower project is located on the West Margin of the Yangtze Paraplatform, with complex cracks under the dam, strong regional neotectonic movement, and relatively stable zone in the near dam reservoir area. The peak acceleration standard of seismic fortification of the dam is $0.2 \mathrm{~g}$, and its upstream and downstream views are shown in Figure 2.

Combined with the failure mode statistics, working principle of gravity dam, and operation performance of Guandi gravity dam, fault tree network of the dam was constructed, as shown in Figure 3.

3.1.2. Weights. Five decision-makers in the fields of design, construction, management, scientific research, and teaching, named DM1 DM5, were invited to judge the failure path index. Table 2 shows the results of the second-level index in Figure 3.

As can be seen from Table 2, there exists a certain difference among five decision-makers when judging the 


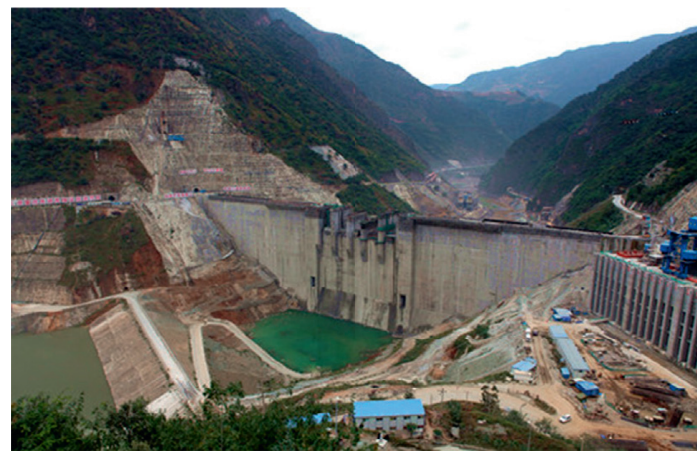

(a)

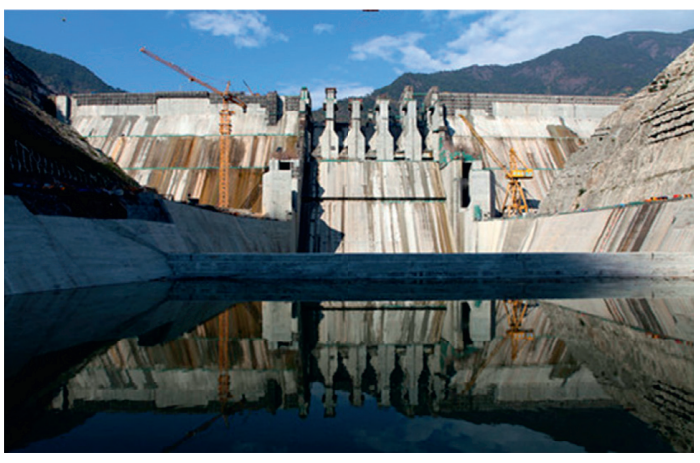

(b)

FIGURE 2: The Guandi gravity dam. (a) Upstream side. (b) Downstream side.

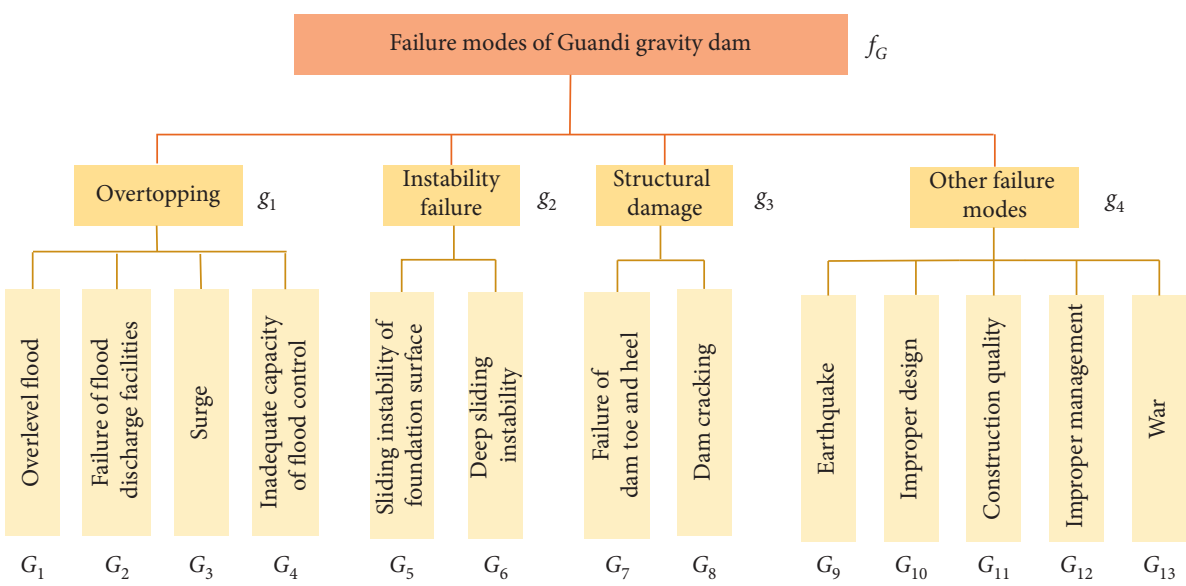

FIgURE 3: Potential failure paths of the Guandi gravity dam.

TABLe 2: Weight results of the second-level index of the Guandi dam.

\begin{tabular}{lccccccc}
\hline Decision-makers & Consistency & Difference & Credibility & \multicolumn{3}{c}{ Interval weight } \\
& & & & $g_{1}$ & $g_{2}$ & $g_{3}$ & $g_{4}$ \\
\hline DM1 & 0.2033 & 0.1918 & 0.2053 & $(0.5830,0.5901)$ & $(0.1738,0.1750)$ & $(0.1918,0.2130)$ & $(0.0404,0.0413)$ \\
DM2 & 0.2035 & 0.1732 & 0.2102 & $(0.5379,0.5991)$ & $(0.1488,0.1575)$ & $(0.2454,0.2791)$ & $(0.0506,0.0512)$ \\
DM3 & 0.2006 & 0.2002 & 0.2005 & $(0.5306,0.5193)$ & $(0.1165,0.1480)$ & $(0.2850,0.3422)$ & $(0.0407,0.0416)$ \\
DM4 & 0.1990 & 0.2335 & 0.1907 & $(0.4959,0.5058)$ & $(0.1029,0.1099)$ & $(0.3527,0.3806)$ & $(0.0314,0.0323)$ \\
DM5 & 0.1936 & 0.2013 & 0.1933 & $(0.6195,0.6305)$ & $(0.1909,0.2378)$ & $(0.1291,0.1316)$ & $(0.0375,0.0381)$ \\
\hline CDB-IAHP & & & & $(0.5480,0.5590)$ & $(0.1468,0.1656)$ & $(0.2403,0.2690)$ & $(0.0403,0.0411)$ \\
Subjective weight & & & & 0.5487 & 0.1726 & 0.2909 & 0.0402 \\
Objective weight & & & & 0.2500 & 0.2500 & 0.2499 & 0.2501 \\
Final weight & & & & 0.5214 & 0.1640 & 0.2764 & 0.0382 \\
\hline
\end{tabular}

relative importance between any two indexes concurrently. The difference could be caused by their experience, knowledge, subjective will, and other influences. In Table 2, the consistency of five decision-makers' judgment matrices for indexes is not an average of 0.20 , which is calculated in a traditional method, but fluctuates from 0.1936 to 0.2035 and with a sum of 1 . The credibility of decision-makers also has changed to an unpredictable value, not a fixed value of 0.20 . Additionally, the subjective weights vary considerably, indicating that the proposed method can dynamically take the differences among decision-makers into accounts based on the judgment matrices. The weight results of other indexes are shown in Table 3. 
Table 3: Weight results of the third-level index of the Guandi dam.

\begin{tabular}{lccccccc}
\hline Indexes & Weight & Indexes & Weight & Indexes & Weight & Indexes & Weight \\
\hline$G_{1}$ & 0.4692 & \multirow{2}{*}{$G_{5}$} & 0.4618 & $G_{7}$ & 0.7157 & $G_{9}$ & $G_{10}$ \\
$G_{2}$ & 0.2920 & 0.1450 & \multirow{2}{*}{$G_{6}$} & 0.5382 & \multirow{2}{*}{$G_{8}$} & 0.1488 \\
\hline$G_{3}$ & 0.0938 & & & & 0.2843 & $G_{11}$ & $G_{12}$ \\
$G_{4}$ & & & & & $G_{13}$ & 0.1166 \\
\hline
\end{tabular}

TABLE 4: Final ranking of failure paths of the Guandi gravity dam.

\begin{tabular}{|c|c|c|c|c|c|c|}
\hline & Second-level indexes & Weight & Third-level indexes & Weight & Path weight & Ranking \\
\hline \multirow{13}{*}{ Failure paths of Guandi gravity dam } & \multirow{4}{*}{$g_{1}$} & \multirow{4}{*}{0.5214} & $G_{1}$ & 0.4692 & 0.2205 & 1 \\
\hline & & & $G_{2}$ & 0.2920 & 0.1687 & 3 \\
\hline & & & $G_{3}$ & 0.1450 & 0.0779 & 5 \\
\hline & & & $G_{4}$ & 0.0938 & 0.0542 & 8 \\
\hline & \multirow[b]{2}{*}{$g_{2}$} & \multirow{2}{*}{0.1640} & $G_{5}$ & 0.4618 & 0.0757 & 7 \\
\hline & & & $G_{6}$ & 0.5382 & 0.0883 & 4 \\
\hline & \multirow{4}{*}{$g_{3}$} & \multirow{2}{*}{0.2764} & $G_{7}$ & 0.7157 & 0.1978 & 2 \\
\hline & & & $G_{8}$ & 0.2843 & 0.0786 & 6 \\
\hline & & \multirow{5}{*}{0.0382} & $G_{9}^{0}$ & 0.4340 & 0.0166 & 9 \\
\hline & & & $G_{10}$ & 0.1488 & 0.0057 & 11 \\
\hline & \multirow[t]{3}{*}{$g_{4}$} & & $G_{11}$ & 0.1166 & 0.0045 & 12 \\
\hline & & & $G_{12}$ & 0.2758 & 0.0105 & 10 \\
\hline & & & $G_{13}$ & 0.0248 & 0.0009 & 13 \\
\hline
\end{tabular}

3.1.3. Ranking. According to the results of the final weights of indexes and the potential failure path fault tree hierarchical graph of the Guandi gravity dam, the weight ratio of different failure paths could be obtained. Table 4 shows the final ranking of failure paths of the Guandi gravity dam.

The top five critical failure paths of the Guandi gravity dam are the following:

(1) Overlevel flood $\longrightarrow$ overtopping $\longrightarrow$ gravity dam failure

(2) Failure of dam toe and heel $\longrightarrow$ structural damage $\longrightarrow$ gravity dam failure

(3) Failure of flood discharge facilities $\longrightarrow$ overtopping $\longrightarrow$ gravity dam failure

(4) Deep sliding instability $\longrightarrow$ instability failure $\longrightarrow$ gravity dam failure

(5) Surge $\longrightarrow$ overtopping $\longrightarrow$ gravity dam failure

Table 5 shows the main failure modes of 130 gravity dams according to the failure cases in the world [24-28]. As seen in Table 5, the percentage of overtopping is up to $33.8 \%$, showing that the overtopping is the main disaster-causing factor. The failure modes of structural damage and instability failure also account for a large proportion. The results obtained from the proposed method in the paper are consistent with the statistical data.

The comparative ranking results of the traditional IAHP method and the proposed method in this paper are shown in Figure 4. Results show that the final ranking of most failure paths does not change, while the ranking of failure paths of $G_{5}-g_{2}-f_{G}$ and $G_{8}-g_{3}-f_{G}$ is reversed. Although the ranking is less affected by these two methods, the weight of each level index and the final weight are different. Taking the final weight for the failure paths as an example, the first three failure paths (1), (2), and (3) in Figure 4) for the Guandi gravity dam are the same by using the IAHP and the CDB-IAHP methods. The final weights are $0.2447,0.1978$, and 0.1522 , as well as $0.2542,0.1593$, and 0.1671 , respectively, implying that the importance of the critical factors and failure paths is different, which has important engineering significance to take engineering and nonengineering measures to reduce the risk of failure paths.

\subsection{Case B: The Pubugou Earth-Rockfill Dam}

3.2.1. Project Review. Pubugou Earth-rockfill dam is the 17 th step in the cascade planning of the mainstream of Dadu River, China. The dam is located near the upper reaches of the Niri River in the middle reaches of the Dadu rivers and across the counties of Hanyuan and Ganluo in the western part of Sichuan Province. The control catchment area is $68512 \mathrm{~km}^{2}$, which accounts for $88.5 \%$ of the area of the Dadu River basin. Pubugou dam is a large-scale hydropower project mainly for power generation, combined with flood control, and blocking and other comprehensive utilization benefits. The normal water level of the Pubugou dam is $850.00 \mathrm{~m}$, the limiting water level in the flood period is $841.00 \mathrm{~m}$, the dead water level is $790.00 \mathrm{~m}$, and the total storage capacity is 5.39 billion $\mathrm{m}^{3}$, for the incomplete annual regulation of the reservoir, as shown in Figure 5.

Combining with the failure mode statistics, working principle of Earth dams, and the related working performance of the Pubugou Earth-rockfill dam, this paper constructed the fault tree network, as shown in Figure 6. 
TABLE 5: Statistics of main failure modes of gravity dams.

\begin{tabular}{lccc}
\hline Failure modes & $\begin{array}{c}\text { Number of } \\
\text { cases }\end{array}$ & $\begin{array}{c}\text { Percentage } \\
(\%)\end{array}$ & Reasons \\
\hline Overtopping & 44 & 33.8 & Dam break of the upstream reservoir, heavy rainfall, failure of flood discharge \\
facilities, etc.
\end{tabular}

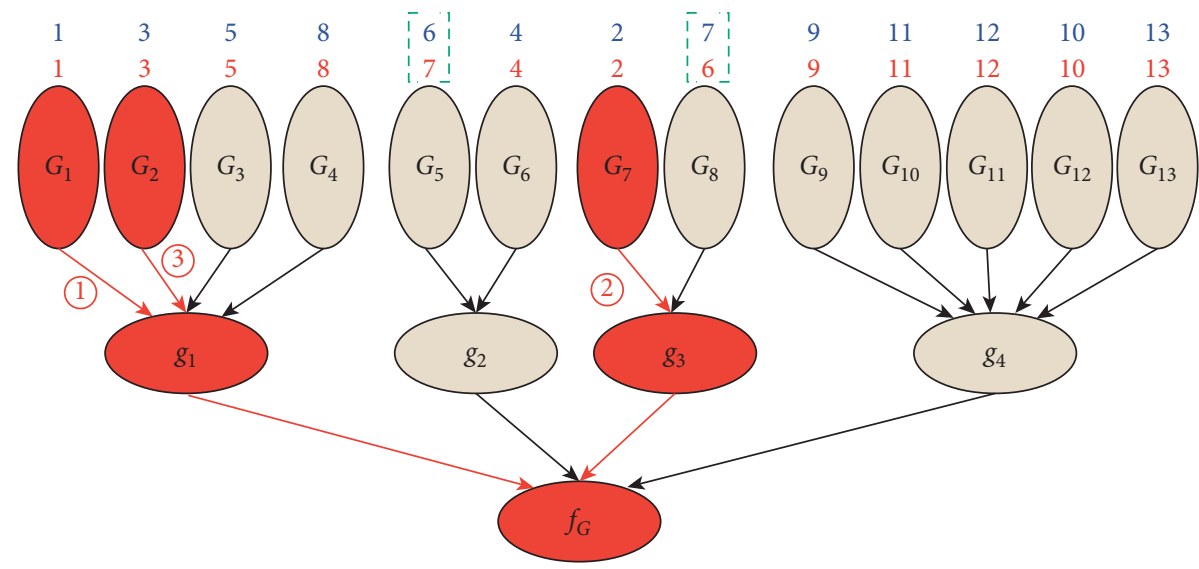

Figure 4: Comparison chart of IAHP and CDB-IAHP methods.

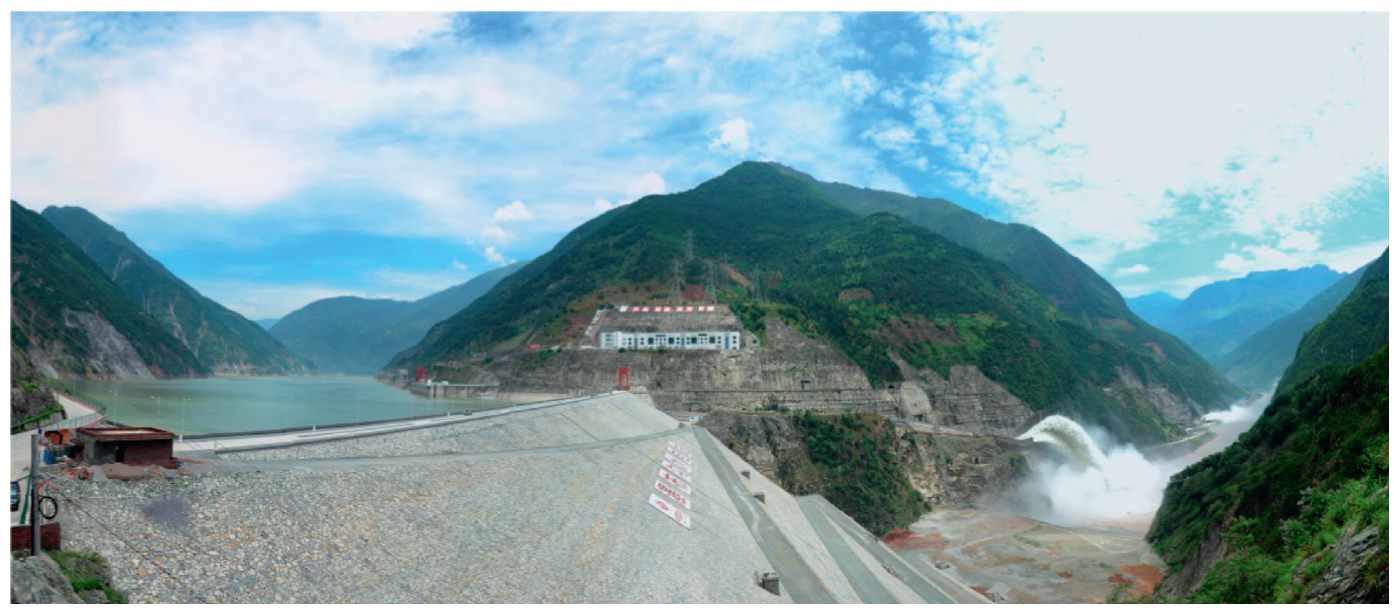

Figure 5: The Pubugou Earth-rockfill dam.

3.2.2. Analysis and Results. Five decision-makers in the fields of design, construction, management, scientific research, and teaching were also invited to judge the failure path indexes, respectively. As seen in Tables 6 and 7, the application effect of CDB-IAHP in the process of Earth dam failure path identification was similar to that of the gravity dam, and the decision-maker had a dynamic difference to different levels of indexes. The top five critical failure paths of the Pubugou Earth-rockfill dam are as follows. The complete ranking is shown in Table 8; the results also have a good relationship with the statistical results:
(1) Overlevel flood $\longrightarrow$ overtopping $\longrightarrow$ Earth dam failure

(2) Leakage of dam body $\longrightarrow$ seepage failure $\longrightarrow$ Earth dam failure

(3) Failure of flood discharge facilities $\longrightarrow$ overtopping $\longrightarrow$ Earth dam failure

(4) Crack $\longrightarrow$ structural failure $\longrightarrow$ Earth dam failure

(5) Surge $\longrightarrow$ overtopping $\longrightarrow$ Earth dam failure

According to the embankment dam failures cases [29], the percentage of overtopping of the embankment dam is 


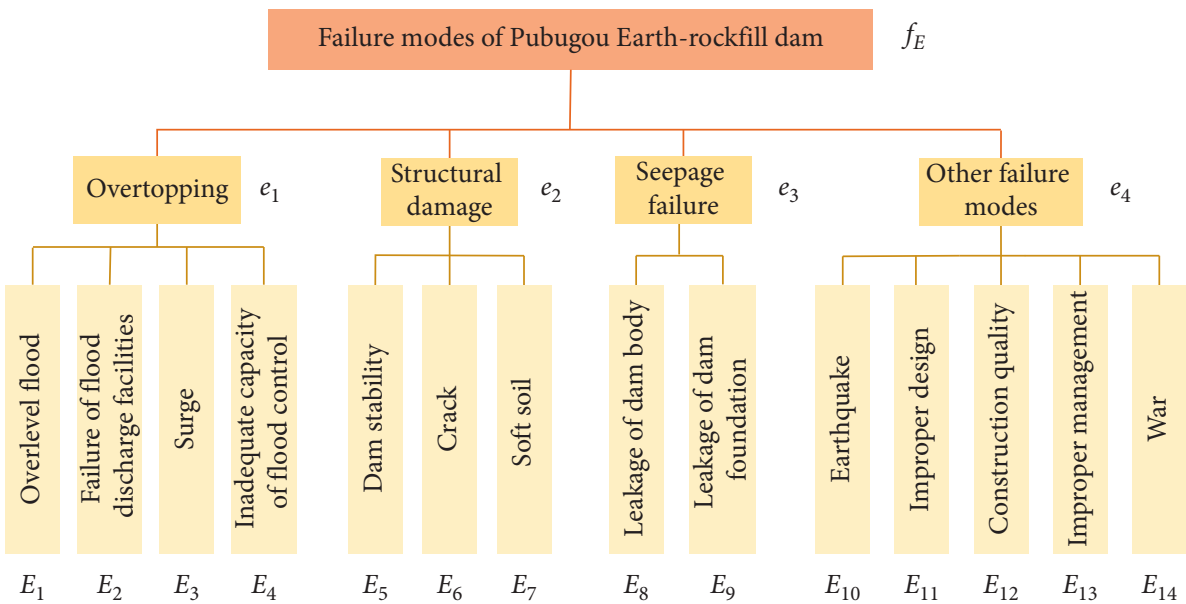

Figure 6: Potential failure paths of the Pubugou Earth-rockfill dam.

Table 6: Weight results of the second-level index of the Pubugou dam.

\begin{tabular}{lccccccc}
\hline Decision-makers & Consistency & Difference & Credibility & \multicolumn{3}{c}{ Interval weight } \\
& & & & $e_{1}$ & $e_{2}$ & $e_{3}$ & $e_{4}$ \\
\hline DM1 & 0.2005 & 0.1945 & 0.2018 & $(0.5684,0.5916)$ & $(0.1671,0.1675)$ & $(0.1990,0.2110)$ & $(0.0402,0.0409)$ \\
DM2 & 0.2000 & 0.1872 & 0.2031 & $(0.5868,0.5898)$ & $(0.2036,0.2085)$ & $(0.1637,0.1643)$ & $(0.0416,0.0422)$ \\
DM3 & 0.2021 & 0.1898 & 0.2046 & $(0.5594,0.5622)$ & $(0.1878,0.1891)$ & $(0.2113,0.2153)$ & $(0.0405,0.0412)$ \\
DM4 & 0.2022 & 0.2011 & 0.2019 & $(0.5657,0.5704)$ & $(0.1300,0.1311)$ & $(0.2622,0.2699)$ & $(0.0353,0.0361)$ \\
DM5 & 0.1953 & 0.2274 & 0.1886 & $(0.4676,0.4712)$ & $(0.1122,0.1146)$ & $(0.3826,0.3857)$ & $(0.0329,0.0338)$ \\
\hline CDB-IAHP & & & & $(0.5544,0.5582)$ & $(0.1609,0.1630)$ & $(0.2417,0.2472)$ & $(0.0382,0.0389)$ \\
Subjective weight & & & & 0.5585 & 0.1729 & 0.2409 & 0.0381 \\
Objective weight & & & & 0.2500 & 0.2500 & 0.2499 & 0.2501 \\
Final weight & & & & 0.5528 & 0.1711 & 0.2383 & 0.0378 \\
\hline
\end{tabular}

Table 7: Weight results of the third-level index of the Pubugou dam.

\begin{tabular}{lccccccc}
\hline Indexes & Weight & Indexes & Weight & Indexes & Weight & Indexes & Weight \\
\hline$E_{1}$ & 0.5067 & $E_{5}$ & 0.1619 & \multirow{2}{*}{$E_{8}$} & \multirow{2}{*}{0.7335} & $E_{10}$ & $E_{11}$ \\
$E_{2}$ & 0.2848 & $E_{6}$ & 0.5224 & \multirow{2}{*}{$E_{9}$} & \multirow{2}{*}{0.2665} & $E_{12}$ & 0.14037 \\
\hline$E_{3}$ & 0.1305 & \multirow{2}{*}{$E_{7}$} & 0.3157 & & $E_{13}$ & 0.1575 \\
$E_{4}$ & 0.0780 & & & & $E_{14}$ & 0.02736 \\
\hline
\end{tabular}

TABLe 8: Final ranking of failure paths of the Pubugou dam.

\begin{tabular}{|c|c|c|c|c|c|c|}
\hline & Second-level indexes & Weight & Third-level indexes & Weight & Path weight & Ranking \\
\hline \multirow{14}{*}{ Failure paths of Pubugou dam } & \multirow{5}{*}{$e_{1}$} & \multirow{5}{*}{0.5528} & $E_{1}$ & 0.5067 & 0.2801 & 1 \\
\hline & & & $E_{2}$ & 0.2848 & 0.1574 & 3 \\
\hline & & & $E_{3}$ & 0.1305 & 0.0721 & 5 \\
\hline & & & $E_{4}$ & 0.078 & 0.0431 & 8 \\
\hline & & & $E_{5}$ & 0.1619 & 0.0277 & 9 \\
\hline & \multirow[t]{2}{*}{$e_{2}$} & \multirow[t]{2}{*}{0.1711} & $E_{6}$ & 0.5224 & 0.0894 & 4 \\
\hline & & & $E_{7}$ & 0.3157 & 0.0540 & 7 \\
\hline & \multirow{4}{*}{$e_{3}$} & \multirow{2}{*}{0.2383} & $E_{8}$ & 0.7335 & 0.1748 & 2 \\
\hline & & & $E_{9}$ & 0.2665 & 0.0635 & 6 \\
\hline & & \multirow{5}{*}{0.0378} & $E_{10}$ & 0.4037 & 0.0153 & 10 \\
\hline & & & $E_{11}$ & 0.1404 & 0.0053 & 13 \\
\hline & \multirow[t]{3}{*}{$e_{4}$} & & $E_{12}$ & 0.1575 & 0.0060 & 12 \\
\hline & & & $E_{13}$ & 0.2736 & 0.0103 & 11 \\
\hline & & & $E_{14}$ & 0.0247 & 0.0009 & 14 \\
\hline
\end{tabular}


$41.0 \%$, and the internal erosion including the dam leakage accounts for $26.6 \%$. The comparison results show that the critical failure paths obtained by the proposed method are almost in line with the statistical data.

To reduce the potential impact of the critical failure paths on dams, not just the Guandi gravity dam and the Pubugou Earth-rockfill dam, some engineering and nonengineering measures can be considered, such as the timely monitoring and early warning of a flood, management of power generation and flood discharge (improving spillway capacity), inspection of dam structure and flood discharge facilities, strengthening the monitoring and management of the dam-foundation system and updating the monitoring equipment, reinforcing the safety and stability of the bank slope near the dam, and scientific and reasonable operation management. The applications of Case A and Case B illustrate that the proposed method shows good applicability for risk analysis and critical failure path mining of dams and has high engineering application value.

\section{Conclusions}

(1) Reasonable investigation of dam risk analysis is of great significance for dam risk identification, risk early warning, and long-term operation. Based on the IAHP and credibility theory, a consistency and difference-based interval analysis hierarchy process (CDB-IAHP) for critical failure paths identification on dams was proposed in this paper.

(2) Considering the decision-maker's dynamic cognitive degree to indexes, the consistency and difference among them on indexes were adopted based on the credibility theory to reduce the influence degree of their experience, knowledge, subjectivity, etc. The subjective weights among decision-makers are more obvious than objective weights, indicating that the proposed method can dynamically adjust the credibility according to different indicators based on the corresponding judgment matrices, rather than being a fixed value.

(3) The feasibility and effectiveness of the proposed method in the identification of critical failure path for gravity dams and Earth dams were verified based on the Guandi gravity dam and the Pubugou Earthrockfill dam. The results illustrate that the proposed method in the paper shows good applicability for risk analysis and critical failure path mining of dams.

\section{Data Availability}

Requests for access to the data of the dam should be made to Kun He, 494097370@qq.com. The calculated data used to support the findings of this study are included in the article.

\section{Conflicts of Interest}

The authors declare that they have no conflicts of interest.

\section{Acknowledgments}

This research was supported by the National Key R\&D Program of China (no. 2018YFC0407103).

\section{References}

[1] T. L. Saaty, The Analytic Hierarchy Process, McGraw-Hill, New York, NY, USA, 1980.

[2] F. Ahmed and K. Kilic, "Fuzzy analytic hierarchy process: a performance analysis of various algorithms," Fuzzy Sets and Systems, vol. 362, pp. 110-128, 2019.

[3] T. Chen, Y. Jin, X. Qiu, and X. Chen, "A hybrid fuzzy evaluation method for safety assessment of food-waste feed based on entropy and the analytic hierarchy process methods," Expert Systems with Applications, vol. 41, no. 16, pp. 7328-7337, 2014.

[4] S. Shi, D. Zhang, Y. Su, C. Wan, M. Zhang, and C. Liu, "A fuzzy-based decision-making model for improving the carrying capacity of ship locks: a three gorges dam case," Journal of Marine Science and Engineering, vol. 7, no. 8, p. 244, 2019.

[5] A. K. Kar, "Revisiting the supplier selection problem: an integrated approach for group decision support," Expert Systems with Applications, vol. 41, no. 6, pp. 2762-2771, 2014.

[6] J. Liu, B. Yang, S. Yuan, L. Li, and L. Duan, "A fuzzy analytic hierarchy process model to assess the risk of disaster reduction due to grouting in coal mining," Arabian Journal of Geosciences, vol. 13, no. 5, p. 227, 2020.

[7] J. H. Choi, T. H. Yoon, J. S. Kim, and Y. I. Moon, "Dam rehabilitation assessment using the Delphi-AHP method for adapting to climate change," Journal of Water Resources Planning \& Management, vol. 144, no. 2, 2018.

[8] Z. K. Li, Y. D. Zhang, H. Y. Guan, and H. J. Song, "Dynamic risk analysis of high rockfill dam during the construction period," Water Resources and Power, vol. 32, no. 10, pp. 138-141+172, 2014, in Chinese.

[9] X. Cheng, S. Wan, and J. Dong, "A new consistency definition of interval multiplicative preference relation," Fuzzy Sets and Systems, 2020, In press.

[10] S. Wan and J. Dong, Decision Making Theories and Methods Based on Interval-Valued Intuitionistic Fuzzy Set, Springer, Singapore, 2020.

[11] G. He, J. Chai, Y. Qin, Z. Xu, and S. Li, "Coupled model of variable fuzzy sets and the analytic hierarchy process and its application to the social and environmental impact evaluation of dam breaks," Water Resources Management, vol. 34, no. 9, pp. 2677-2697, 2020.

[12] Y. Fang, X. Zheng, H. Peng, H. Wang, and J. Xin, “A new method of the relative membership degree calculation in variable fuzzy sets for water quality assessment," Ecological Indicators, vol. 98, pp. 515-522, 2019.

[13] M. Dağdeviren and İ. Yuksel, "Developing a fuzzy analytic hierarchy process (AHP) model for behavior-based safety management," Information Sciences, vol. 178, no. 6, pp. 1717-1733, 2008.

[14] S. Zhang, B. Sun, L. Yan, and C. Wang, "Risk identification on hydropower project using the IAHP and extension of TOPSIS methods under interval-valued fuzzy environment," Natural Hazards, vol. 65, no. 1, pp. 359-373, 2013.

[15] O. Kular and C. Kahraman, "Fuzzy multi-attribute selection among transportation companies using axiomatic design and analytic hierarchy process," Information Sciences, vol. 170, no. 2-4, pp. 191-210, 2005. 
[16] J.-B. Yang, "Rule and utility based evidential reasoning approach for multiattribute decision analysis under uncertainties," European Journal of Operational Research, vol. 131, no. 1, pp. 31-61, 2001.

[17] P. Liu, Y. L. Zhang, X. T. Yan, and X. H. Kuang, "The method of interactive group decision-making for AHP based on experts' dynamic weights," Mathematics in Practice and Theory, vol. 13, pp. 85-90, 2007, in Chinese.

[18] X. Z. Qin, X. H. Wang, and D. L. Yang, "Credit degree method of group decision making in AHP (I)," Systems EngineeringTheory \& Practice, vol. 7, pp. 89-93, 1999.

[19] X. Z. Qin, X. H. Wang, and D. L. Yang, "Credit degree method of group decision making in AHP (II)," Systems EngineeringTheory \& Practice, vol. 5, pp. 76-80, 2000.

[20] H. Zhou, Y. Yuan, C. Liu, C. Wu, and M. Zhang, "Extension model for safety appraisal of existing concrete members based on an improved comprehensive weighting method," Advances in Civil Engineering, vol. 2018, Article ID 1217543, 15 pages, 2018.

[21] Y. Wei, J. Liu, and X. Wang, "Concept of consistence and weights of the judgement matrix in the uncertain type of AHP," Systems Engineering-Theory \& Practice, vol. 14, no. 4, pp. 16-22, 1994.

[22] R. Pan, L. Zou, and Y. Hou, "The method of uncertain AHP based on expert credibility and its application," Systems Engineering, vol. 26, no. 10, pp. 101-106, 2008, in Chinese.

[23] Y. Yi, Research on the Design Method of Gas Pipeline Based on Risk Assessment, Southwest Petroleum Institute, Chengdu, China, 2005, in Chinese.

[24] O. G. Ingles, "A short study of dam failures in Australia, 1857-1983," Civil Engineering Systems, vol. 1, no. 4, pp. 190-194, 1984.

[25] S. Laginha and J. Coutinho-Rodrigues, "Statistics of dam failures: a preliminary report," International Water Power and Dam Construction, vol. 41, no. 4, pp. 30-34, 1989.

[26] Y. Xu, "Analysis of dam failures and diagnosis of distress for dam rehabilitation," Ph.D. thesis, The Hong Kong University of Science and Technology, Hong Kong, 2010.

[27] P. Chigare and A. S. Wayal, "Dam overtopping risk analysis modeling," International Journal of Innovative Research in Science \& Engineering, vol. 2, no. 6, pp. 455-462, 2013.

[28] L. Zhang, M. Peng, and D. Chang, Dam Failure Mechanisms and Risk Assessment, pp. 53-56, John Wiley \& Singapore Pte., Ltd., Singapore, 2016.

[29] L. M. Zhang, Y. Xu, and J. S. Jia, "Analysis of earth dam failures: a database approach," Georisk: Assessment and Management of Risk for Engineered Systems and Geohazards, vol. 3, no. 3, pp. 184-189, 2009. 